\title{
The Optical Study of ZnO Thin Films at Different Times of Annealing and Varying Temperatures Prepared by Chemical Bath Deposition.
}

\author{
J.I.Onwuemeka, O.K. Nwofor, N.C. Nwulu, I.E. Nwosu, F.M. Ezike and \\ C.G. Obizo \\ Department of Physics/Industrial Physics, Imo State University, Owerri Nigeria.
}

\begin{abstract}
A research on the Deposition and Characterization of ZnO Thin Films by Chemical Bath Deposition Technique using Ammonia $\left(\mathrm{NH}_{3}\right)$ as a complexing agent. Thin films of $\mathrm{ZnO}$ are deposited onto glass substrates at room temperature for 5hours. The optical properties of the films were measured using Double Beam UV-Spectrophotometer with serial number UV061514, Rutherford Back Scattering Spectroscopy (RBS) analysis revealed that the thin filmshave percentage ratios of the elements of $\mathrm{Zn} / \mathrm{O}, 47 / 53$ as annealed for 3hours at the temperature of $250^{\circ} \mathrm{C}$ and $\mathrm{Zn} / \mathrm{O}, 48.8 / 51.2$ as annealed for 1 hour at the temperature of $150^{\circ} \mathrm{C}$. The thicknesses are $80 \mathrm{~nm}$ for 3hours and 150nm for lhour asannealed samples at $250{ }^{\circ} \mathrm{C}$ and $150^{\circ} \mathrm{C}$ respectively. It was found that $\mathrm{ZnO}$ thin films exhibits n-type conduction. Optical band gap values of the twosamples are $3.1 \pm 0.05 \mathrm{eV}$ as annealed for 3hours and $3.3 \pm 0.05 \mathrm{eV}$ as annealed for lhour with an average of $3.2 \pm 0.05 \mathrm{eV}$. Other optical properties calculated from transmittance using appropriate equations are absorbance, reflectance, band gap, absorption coefficient, optical conductivity, refractive index and extinction coefficient.

Keywords: Annealing, absorption coefficient, extinction coefficient, absorbance, band gap substrates.
\end{abstract}

\section{Introduction}

Advances in the area of alternative energy technology will ensure a stable electricity which will lead to smooth transition away from fossil fuels and nuclear energy, that comprise about $93 \%$ of the world's energy budget with a negligible contribution from solar energy. $\mathrm{ZnO}$ thin films have valued properties such as high optical transparency in the visible and near-infrared region of electromagnetic spectrum [1], chemical stability in hydrogen plasma [2], high refractive index [3], and wide band gap semiconductor [4]. The thin films of the metallic oxide have wide range of applications such as antireflection coating [5], surface acoustic wave devices [6], band pass filter [7], laser deflectors using piezoelectric and piezo-optic properties [8].

$\mathrm{ZnO}$ thin films can be produced by different methods such as pulse laser deposition[9], spray pyrolysis[10], sol-gel technique[11],chemical bath deposition[12]. The films in this study are grown by chemical bath deposition (CBD) which creates a thin film on a solid substrate via a reaction in a liquid solution. The CBD method is inexpensive, easy to prepare and its necessary vessels can be found in an ordinary chemistry laboratory [13].

In this work, we report the study of the optical properties of $\mathrm{ZnO}$ thin films at varying annealing times and temperatures prepared by chemical bath deposition on glass substrates.

\section{Experiments}

$\mathrm{ZnO}$ thin films were deposited on glass substrates by chemical bath deposition based on the reaction between $\mathrm{ZnCl}_{2(\mathrm{aq})}, \mathrm{NaOH}_{\text {(aq) }}$ and with $\mathrm{NH}_{3(\mathrm{aq})}$ as complexing agent according to the equation;

$$
\begin{aligned}
& \mathrm{ZnCl}_{2}+4 \mathrm{NH}_{3}+\mathrm{H}_{2} \mathrm{O} \longrightarrow\left[\mathrm{Zn}\left(\mathrm{NH}_{3}\right)_{4}\right]^{2+}+\mathrm{H}_{2} \mathrm{O}+2 \mathrm{Cl}^{-} \\
& {\left[\mathrm{Zn}\left(\mathrm{NH}_{3}\right)_{4}\right]^{2+}+2 \mathrm{NaOH} \longrightarrow \mathrm{ZnO}+4 \mathrm{NH}_{3}+2 \mathrm{Na}^{-}+\mathrm{OH}^{-}}
\end{aligned}
$$

An excess aqueous ammonium was added to $20 \mathrm{ml}$ of $0.5 \mathrm{M}$ solution of $\mathrm{ZnCl}_{2}$ to form a white $\left.\left(\mathrm{Zn}^{2} \mathrm{NH}_{3}\right]_{4}{ }^{2+}\right)$ which dissolved completely on stirring to form a clear solution. $10 \mathrm{ml}$ of $1 \mathrm{M}$ solution of $\mathrm{NaOH}$ was finally added for complete formation of $\mathrm{ZnO}$ thin films in an alkaline medium. The $\mathrm{pH}$ of the final solution was measured to be 9.3 and was done at room temperature. Glass substrates were then immersed vertically into the final solution which were made in $50 \mathrm{ml}$ beaker and optimum depositions were obtained after five hours 


\section{Results and Discussion}

Many samples were deposited under different set of conditions of reactant concentrations, temperature, and $\mathrm{pH}$ of the solution. Two slides were immersed in each beaker representing a given set of conditions. Optimum results were obtainedon the slides under the stated conditions below:

Concentration and volume of reactants; $20 \mathrm{ml}$ of $0.5 \mathrm{M} \mathrm{ZnCl}_{2(\mathrm{aq})}+4 \mathrm{ml}$ of $3 \mathrm{M} \mathrm{NH}_{3(\mathrm{aq})}+10 \mathrm{ml}$ of $1 \mathrm{MNaOH}_{(\mathrm{aq})}$

Deposition temperature; $23^{\circ} \mathrm{C}$

PH of final solution; 9.3

Deposition time; 5 hours

Annealing temperatures; $250^{\circ} \mathrm{C}$ and $150^{\circ} \mathrm{C}$ for each of the two representative samples

Annealing time; 3 hour and 1 hours for, each of the two representative samples.

Volume ratio; 20:4:10 which gave the desired depositions.

\section{Composition and thickness measurements}

Two representative samples were selected out of the four samples deposited under the same conditions at room temperature of $23^{\circ} \mathrm{C}$. The two samples were subjected to Rutherford Back Scatteringspectroscopy analysis (RBS). The presence of $\mathrm{Zn}^{2+}$ and $\mathrm{O}^{-2}$ were confirmed in the ratio of 0.47:0.53 by number of atoms. This implies that $47 \%$ of $\mathrm{Zn}^{2+}$ and $53 \%$ of $\mathrm{O}^{2-}$ are present in the sample annealed for 3hours at $250^{\circ} \mathrm{C}$ as shown in Fig.3. Also, the percentage compositions of the sample annealed for 1 hour at the temperature of $150^{\circ} \mathrm{C}$ are 48.8\% Zinc and 51.2\% oxygen as shown in Fig.2. The thicknesses of the films were also determined to be $150 \mathrm{~nm}$ and $80 \mathrm{~nm}$ for the samples annealed for one hour and three hours respectively from the RBS test as shown in Figs. 2 and 3.

Fig.1, is the RBS of the uncoated glass slide.

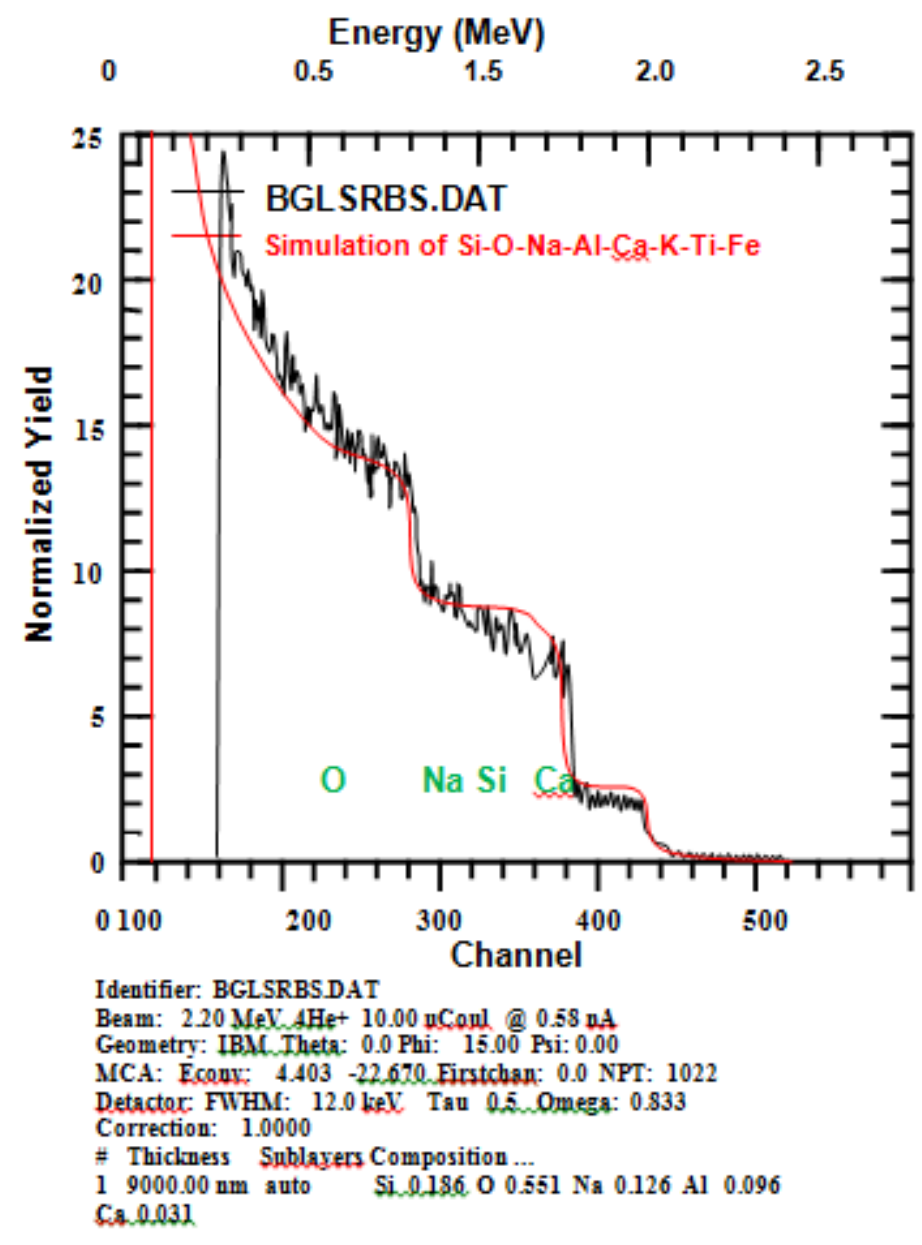

Fig. 1: RBS result for blank glass subst ate 

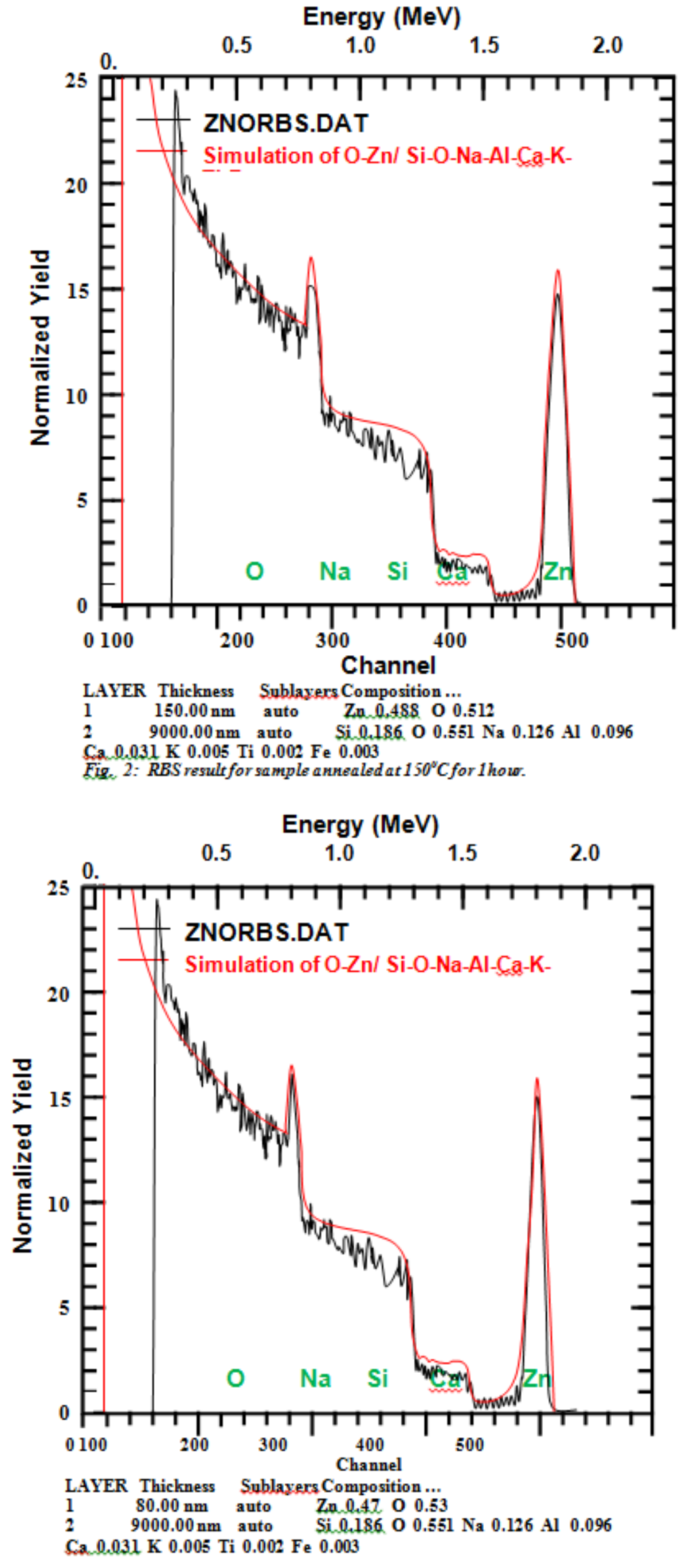

Fig.3: RBS result for sample annealed at $250^{\circ} \mathrm{C}$ for 3 hows. 
Optical properties

Transmittance

The transmittance, which is the ratio of the incident intensity to the transmitted intensity of the radiation was measured using UVI double beam Spectrophotometer with serial number 061514.

Absorbance, reflectance and other optical properties were calculated from the values obtained from the transmittance values using appropriate equations.

For the sample annealed at $250^{\circ} \mathrm{C}$ for 3 hours transmittance decreased from 0.70 to 0.66 as the wavelength increased from $368 \mathrm{~nm}$ to $940 \mathrm{~nm}$. For the other sample annealed at $150^{\circ} \mathrm{C}$ for 1 hour, transmittance decreased from 0.819 to 0.804 as the wavelength increased from $366 \mathrm{~nm}$ to $940 \mathrm{~nm}$. This means that $\mathrm{ZnO}$ can be used as window in UV optics, since it has higher transmittance in UV region. Also it can be used as infrared shield. The graphs for the two samples are shown in Figs.4.

\section{Band gap}

The energy gap of $3.1 \pm 0.05 \mathrm{eV}$ and $3.3 \pm 0.05 \mathrm{eV}$ for the sample annealed at $250^{\circ} \mathrm{C}$ for 3 hour and $150^{\circ} \mathrm{C}$ for 1hour respectively as shown in Fig.5were achieved.

$\mathrm{ZnO}$ have a relatively large direct band gap of $3.3 \pm 0.05 \mathrm{eV}$ at room temperature. Advantages associated with a large band gap include higher breakdown voltage ability to sustain large electric current, lower electronic noise, high temperature and high power operation. While those with lower band gap (i.e. below $3.3 \mathrm{eV}$ ) can be use as absorber layers in solar cells.

The $\mathrm{ZnO}$ thin films have average band gap of $3.2 \pm 0.05 \mathrm{eV}$ which is approximately a direct band gap of $\mathrm{ZnO}$ thin films [4].

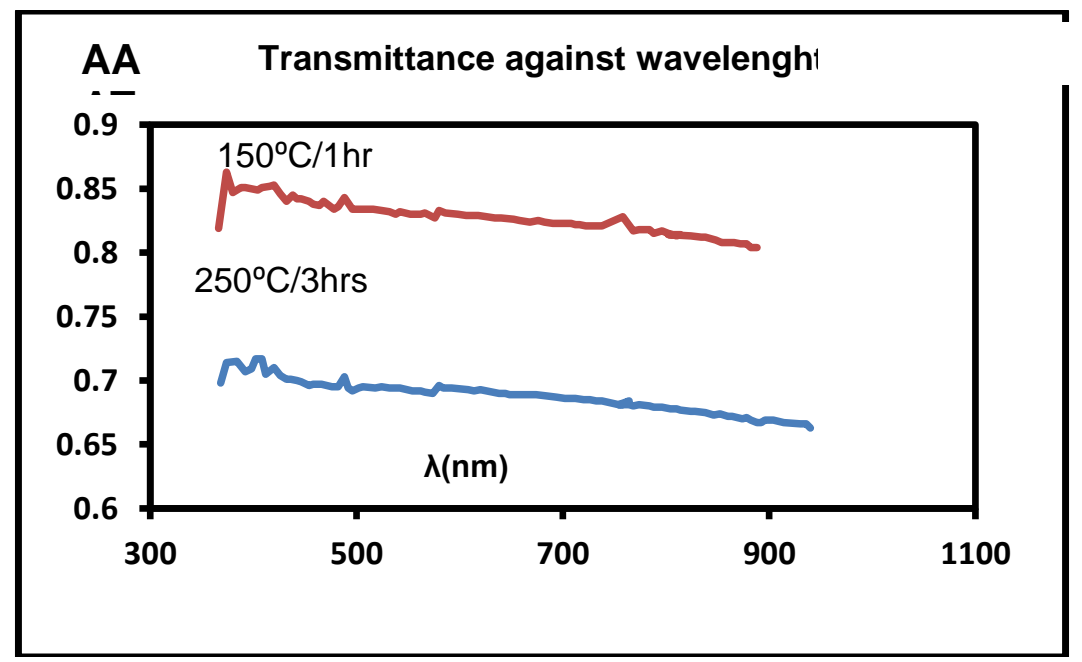

Fig 4: Graph of Transmittance against Wavelength

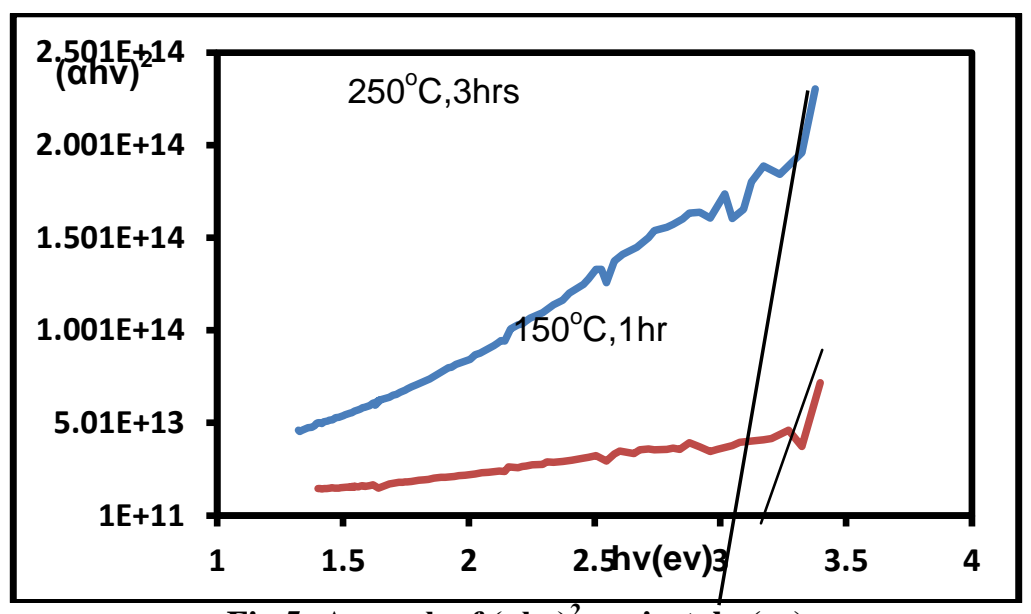

Fig 5: A graph of $(\alpha h v)^{2}$ against hv(ev)

\section{Conclusion}

$\mathrm{ZnO}$ thin films were deposited onto glass substrates using chemical bath method (CBD). CBD is known to be simple, low temperature and inexpensive large area deposition technique. It is one of the 
preparation of compound semiconductors from aqueous solutions such as $\mathrm{Cds}, \mathrm{CdSe}, \mathrm{CdO}, \mathrm{ZnS}, \mathrm{ZnSe}$ and ZnO.It gives good deposits on suitable substrates by controlled precipitation of the compound from the solution. Thin films are made for different purposes both for optical, electronics, electrical and other passive applications.

\section{Acknowledgement}

We are grateful to laboratory officers of ObafemiAwolowo University Ile-Ife in the persons of Prof. E.I. Obiajunwa of Centre for Energy Research and Development and Mr.Akiola E. A. of Central Science Laboratory for their assistance in the successful characterization of this work.

\section{Reference}

[1] A. Martin, J.P. Espinsos, A. Justo, J.P. Holgado, F. Yubero, A.R. Gonzalez-Elipe, Surf. Coat.Technol. 151-152 (2002) 289.

[2] C.G. Grangvist, Thin Solid Film, 193-194 (1990) 730.

[3] Z. Jwei, Z. Liangying, Y. Xi, Ceram. Int. 26 (2000) 883.

[4] X.W. Sun, H.S. Kwok, J. Appl. Phys. 408-411 (1999) 86

[5] T. Komaru, S. Shimizu, M. Kambe et al, Jpn J. Appl. Phys., 38 (1999) 5796.

[6] S. Whangbo, et al, Journal of the Korean Physical Soc. 456-460 (2000) 37(40.

[7] T.K. Subramanyam, B.S. Naidu, S. Uthanna, Cyst. Res. Technol. 1193-1202 (2000) 35.

[8] D. Boa, H. Gu, A. Kuang, Thin Solid Films, 37-39 (1988) 312.

[9] J.F. Muth, R.M. Kolbas, A.K. Sharma, S. Oktyabrsky, J. Narayan, J. Appl. Phys. 85 (1999) 353

[11] G. Santana, et al, Superficies Y Vacio 300-320 (1999) 9.

[12] J.I. Onwuemeka, "Deposition and Characterization of ZnO Thin Films for Possible Device Applications" M.Sc. Thesis, Federal University of Technology Owerri, Nigeria.

[13] A. Tunasevski, semicond. Sci.Technol. 501-505 (2003) 18. 